\title{
INFLUENCE OF CORROSIVE ENVIRONMENT ON FATIGUE CRACK INITIATION IN ALLOYS FOR STEAM TURBINE BLADES
}

B. Knosp*, H. Saisse* and A. Coulon**

*Laboratoires de Marcoussis, CR-CGE, Route de Nozay, 91460 Marcoussis, France
${ }_{* *}$ Alsthom-Atlantique, Avenue des Trois Chenes, 90001 , Belfort, France

ABSTRACT

The titanium alloy TA6V is under consideration to replace $12 \%$ chromium steels in some cases for the manufacture of blades for low pressure steam turbines. Tests were therefore conducted to compare the notch crack initiation strength (in three and a TA6V alloy forge in the " $\alpha+\beta$ " two phase region a i the $\beta$ phase. From the results of these tests, it may be considered that the behaviour of TA6V is independent of the medium investigated. However, the steel's crack initiation strength deteriorates in the most corrosive of the three media investigated $\left(1 \mathrm{~g} / \ell \mathrm{NaCl}, \mathrm{PH} 9, \theta=80^{\circ} \mathrm{C}\right)$ due to the appearance of corrosion pits In this medium $\mathrm{TA} 6 \mathrm{~V}$ " 8 " seems to show the the three materials tested.

KEYWORDS

Crack initiation, $\Delta \mathrm{K}$ threshold, stress corrosion, titanium alloys, $12 \% \mathrm{Cr}$ steel, steam turbine blades.

\section{INTRODUCTION}

The fatigue strength and erosion and corrosion resistance properties of the titanium alloy TA6V, together with its low density, point to the possibility of its use to manufacture LP steam turbine blades, instead of the $12 \%$ chromium steels used at present. Depending on the heat treatment selected, the microstructure of TA6V may be equiaxial or acicular.

In the case of gas turbines, for which this alloy is already used, the microstructures of the Widmanstatten type are prohibited due to their mediocre fatigue behaviour (Duncan, 1981). However, according to a bibliographic study made by Wood (1977) on titanium and its alloys, it appears that this poor behaviour of acicular microstructures occurs more in low-cycle fatigue than in high-cycle fatigue. Moreover, certain investigations (Eylon, 1976) seem to indicate that the fatigue behaviour of
notched test specimens of TA6V with an acicular structure is better than the notched test specimens of TA6V with an acicular 
As in the case of blades for steam turbines, the high-cycle fatigue strength is the to rimary criterion, and, since the cracks tend to initiate from notches, we decided that maf structure) $1 A 6 \mathrm{~V}$ alloy forged either in the $" \alpha+\beta "$ two-phase region (equiaxial ted with $R=0.5$ an $\beta$ hase (Widmanstatten type structure). This study was conducsimulate the performed to behaviour of the

\section{MATERIALS INVESTIGATED}

The materials investigated were a $12 \%$ chromium steel type $Z 19$ CD12-1 (according and in the Standard) and a TA6V alloy forged in the " $\alpha+\beta "$ two-phase regio sitions are given in Tables 1 and 2 .

The steel blades underwent the following heat treatment :

- austenitization at 1045 to $1050{ }^{\circ} \mathrm{C} /$ air quench,

- tempering at 640 to $660{ }^{\circ} \mathrm{C} / 2$ to 4 hours/air cooling.

After forging, the TA6V blades were kept for 1 to 2 hours at $700{ }^{\circ} \mathrm{C}$ and cooled

The mechanical properties resulting from these treatments are summarized in Table 3, and the microstructures obtained are shown in Fig. 1.

\section{EXPERIMENTAL}

\section{Testing Equipment} The tests were performed on an Instron 1273 servo-hydraulic fatigue machine,
capacity $100 \mathrm{kN}$, equipped with :

- a thermostatically controlled corrosion cell used to operate in aqueous medium up to $80^{\circ} \mathrm{C}$

a DF 20 type crack initiation detector sold by Instruments SA, its operation based on an a.c. $(50 \mathrm{~Hz})$ potential drop method,

- a binocular microscope with $50 X$ magnification, mounted on a microTest Specimens

Crack initiation was investigated with notched bend test specimens (Fig. 2) called $\mathrm{KF} 10 \mathrm{~A}$. The notch profile was selected to obtain a $\mathrm{K}_{\mathrm{Tn}}$ of about 2 , similar to
those routinely encountered in the blades. The stress concentration factor $\mathrm{K}$.
the notch selected was the notch selected was calculated from Peterson (1974) and was equal to 2.02 . The notch was machined by electro-erosion and its surface polished mechanically (finishing Compact CT 25 chevron test specimens were employed for crack growth threshold
tests.
TABLE 1.Z19 CD12-1 Composition (wt \%)

\begin{tabular}{lccccccccc}
\hline & $\mathrm{C}$ & $\mathrm{S}$ & $\mathrm{P}$ & $\mathrm{Si}$ & $\mathrm{Mn}$ & $\mathrm{Cr}$ & $\mathrm{Ni}$ & $\mathrm{Mo}$ & $\mathrm{V}$ \\
\hline Smith Clayton & 0,17 & 0,04 & 0,012 & 0,29 & 0,45 & 12,1 & 0,76 & 0,94 & 0,03 \\
Thyssen & 0,18 & 0,06 & 0,025 & 0,29 & 0,52 & 12,3 & 0,59 & 0,81 & 0,02 \\
\hline
\end{tabular}

TABLE 2.TAGV composition (wt \%)

\begin{tabular}{ccccccc}
\hline $\mathrm{Fe}$ & $\mathrm{C}$ & $\mathrm{O}$ & $\mathrm{N}$ & $\mathrm{H}$ & $\mathrm{Al}$ & $\mathrm{V}$ \\
\hline 0,08 & 0,008 & 0,16 & 0,008 & 0,0024 & 6,1 & 3,8 \\
0,13 & 0,014 & 0,19 & 0,019 & 0,0033 & 6,3 & 4,1 \\
\hline
\end{tabular}

TABLE 3.Mechanical Properties

\begin{tabular}{lcccc}
\hline \multicolumn{1}{c}{ Material } & $\begin{array}{l}0,2 \% \text { Proof } \\
\text { Strength (MPa) }\end{array}$ & $\begin{array}{c}\sigma_{\text {ult }} \\
(\mathrm{MPa})\end{array}$ & $\begin{array}{l}\text { Elongation to } \\
\text { Fracture (\%) }\end{array}$ & $\begin{array}{l}\text { Reduction } \\
\text { of area (\%) }\end{array}$ \\
\hline Z19 CD12-1 & & & & \\
Smith Clayton & 745 & 925 & 17 & 53 \\
Thyssen & 655 & 848 & 17,6 & 51 \\
" $\alpha+\beta$ " forged & 854 & 925 & 12 & 36 \\
TA6V & 932 & 980 & 18 & 42 \\
" $\beta$ " forged & 810 & 903 & 10 & 15 \\
TA6V & 855 & 950 & 10 & 23 \\
\hline
\end{tabular}
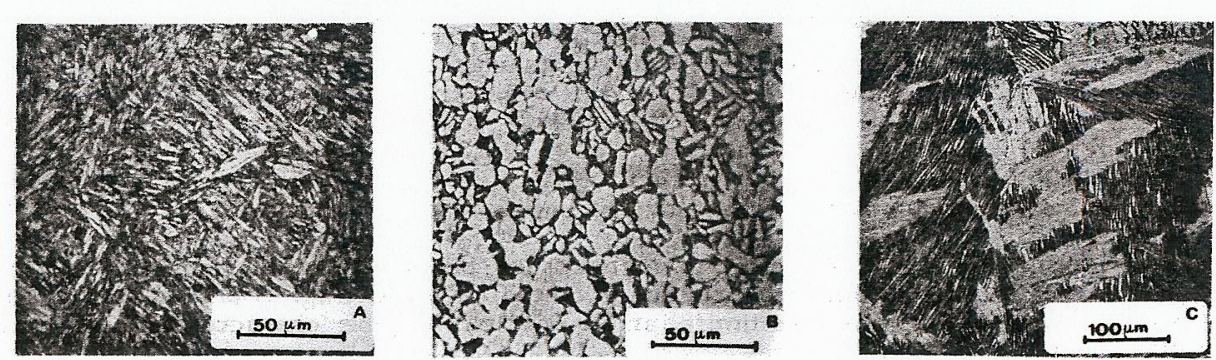

Fig. 1. Micrographs of the alloys studied

A) $219 \mathrm{CD} 12-1$

B) $" \alpha+\beta$ " forged TA6

C) " $\beta$ " forged TA6V 
Media investigated

Tests were conducted in the following media :

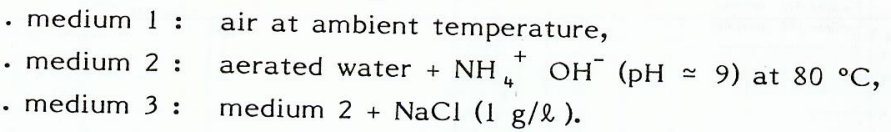

\section{CRACK INITIATION TESTS}

\section{Test Procedure}

The KF 10A test specimens were bend stressed at four points in the following . inner span $28 \mathrm{~mm}$, outer span $84 \mathrm{~mm}$

- sine force signal with frequency between 10 and $100 \mathrm{~Hz}$

- ratio $\mathrm{R}=0.5$,

- media investigated $: 1,2$ and 3 .

Crack initiation was identified using a DF 20 detector, of which the detection limit corresponds to a crack area of about $0.5 \mathrm{~mm}^{2}$.

\section{Results}

The results are presented in the $\Delta S=f(\log N a)$ diagrams where :

- $\mathrm{Na}$ is the number of cycles to initiation

- $\Delta \mathrm{S}=\mathrm{S}_{\max }-\mathrm{S}_{\min }$ is equal to $\mathrm{K}_{\mathrm{Tn}} \Delta \sigma_{n}$ and was taken as the initiation parameter.

The results concerning $Z 19 \mathrm{CD} 12-1$ steel are presented in Fig. 3. The crack initiation trength of this steel appears to decline as the medium becomes more corrosive. The degradation observed between medium $2(\Delta S D=675 \mathrm{MPa})$ and medium $\Delta S_{D}=500 \mathrm{MPa}$ ) was attributed to the for medium (Fig. 4) where the crack initiated.

However, in our opinion, the difference observed between medium 1 and medium 2 in 1983) (1) $\mathrm{R}=0.1$ and $\mathrm{R}=0.7$, the initiation endurance limit

To conclude, the crack initiation strength of 219 CD12-1 deteriorates in medium (presence of $\mathrm{NaCl}$ ) due to the appearance of corrosion pits.

For TA6V, it may be considered that the crack behaviour is independent of the (Fig. 6) considered, whether its structure is of the equiaxial (Fig. 5) or Widmanstatten following values of $\triangle S$ :
. TA6V" $\alpha+\beta "$
$\Delta S_{D} \simeq 350 \mathrm{MPa}$,
- TA6V " $B "$
$\Delta S_{\mathrm{D}} \simeq 500 \mathrm{MPa}$

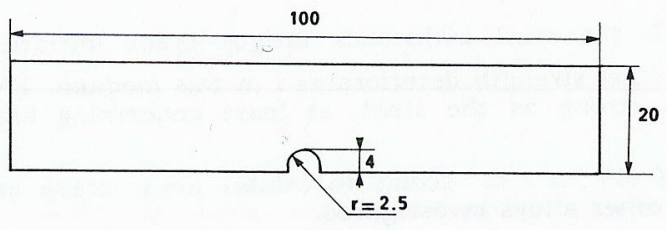

Fig. 2. KF $10 \mathrm{~A}$ specimen
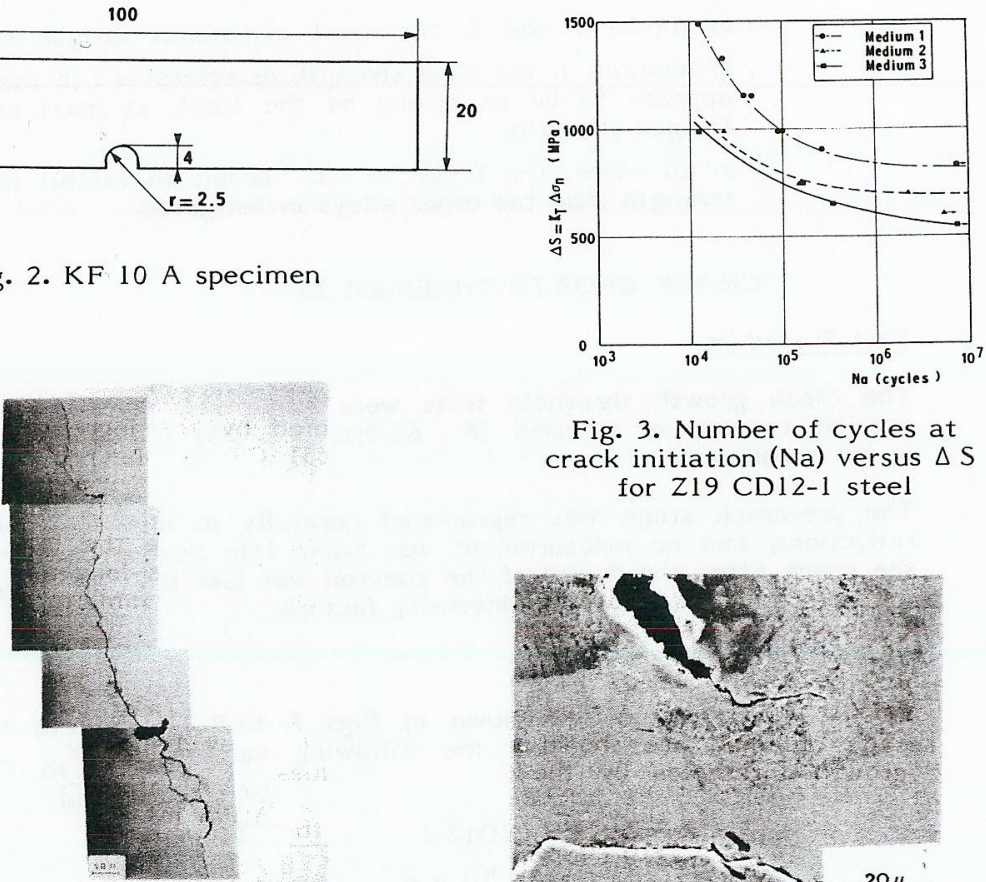

Fig. 3. Number of cycles at Fig. 3. Number of cycles at for Z19 CD12-1 steel

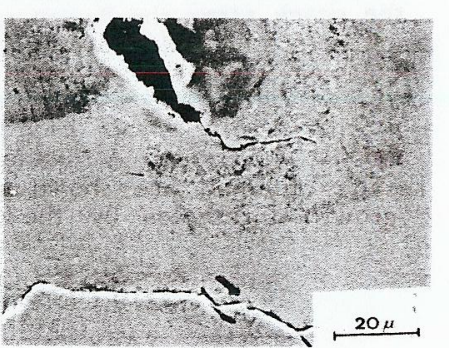

Fig. 4. Z19 CD12-1 steel in medium 3. Corrosion pits observed at the notch root.

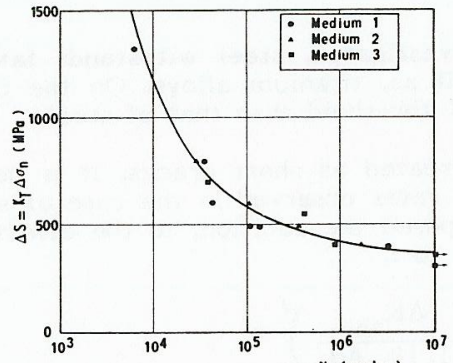

Fig. 5. Number of cycles at crack initiation ( $\mathrm{Na}$ ) versus $\Delta S$ for $" \alpha+\beta "$ forged TA6V

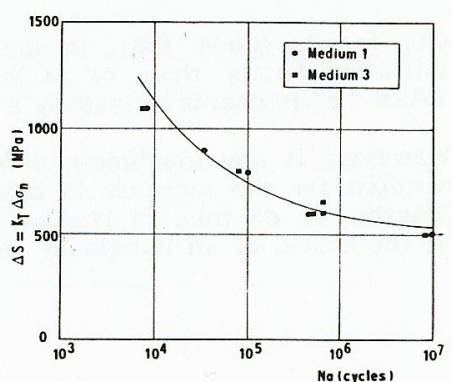

Fig. 6. Number of cycles at crack initiation (Na) versus $\Delta S$ 


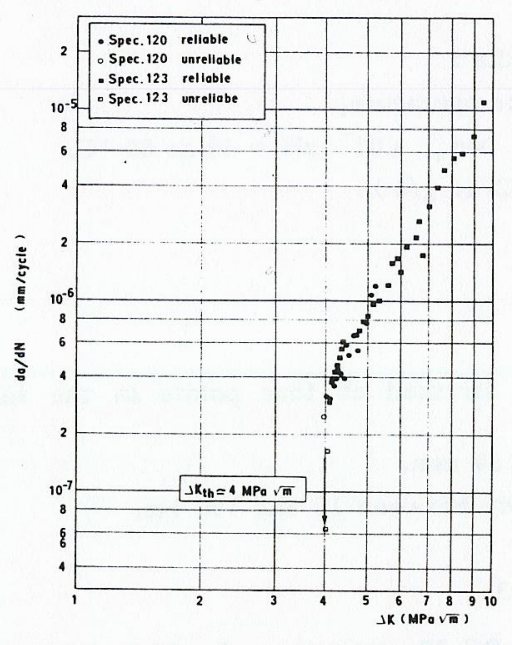

Fig. 7. Crack growth rate (da/dN) versus $\triangle \mathrm{K}$ for $\mathrm{Z} 19 \mathrm{CD} 12-1$ steel

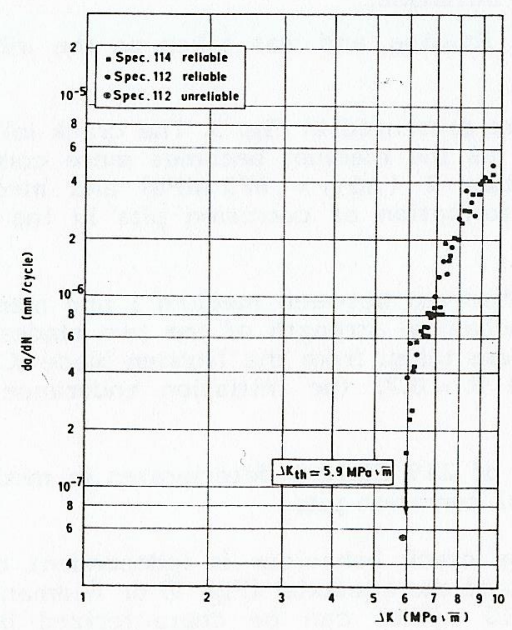

Fig. 9. Crack growth rate $(\mathrm{da} / \mathrm{dN})$ versus $\triangle K$ for " $B$ " forged TAGV

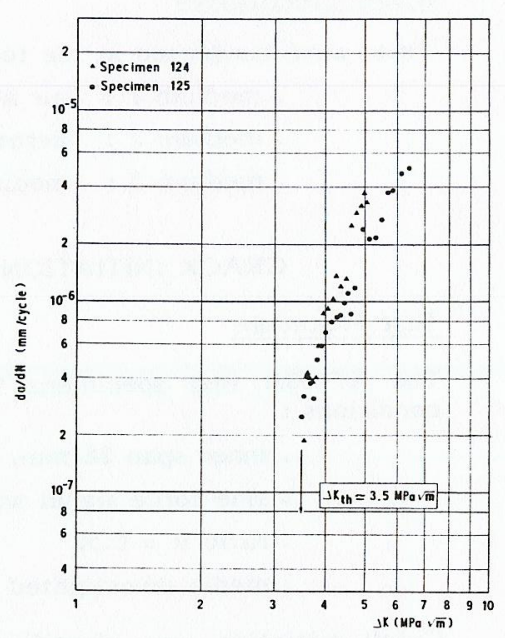

Fig. 8. Crack growth rate (da/dN) versus $\Delta K$ for " $\alpha+\beta$ " forged TA6V

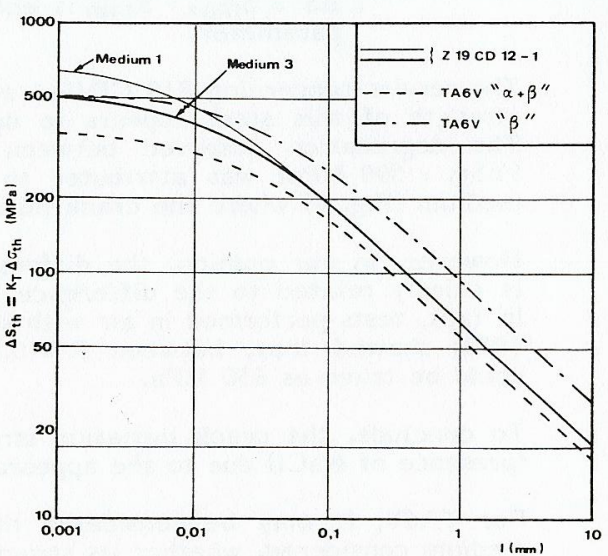

Fig. 10. Effect of crack length ( $($ ) on threshold stress range $\left(\Delta S_{t h}\right)$ for
Furthermore, Topper (1982) showed that the endurance limit of a specimen with a

blunt notch could be considered as equal to $\Delta \sigma_{\mathrm{D}} / \mathrm{K}_{\mathrm{T}}$. In other words, $\Delta \sigma_{\mathrm{D}}$ is
equal to $\Delta \mathrm{S}_{\mathrm{D}}$.

$$
\begin{aligned}
& \text { alloy } \\
& \begin{array}{ll}
Z 19 \mathrm{CD} 12-1 & \frac{\Delta \mathrm{K}_{\text {th }}}{4}(\mathrm{MPa} \sqrt{\mathrm{m}}) \\
\text { TA6V " } \alpha+\beta " & 3.5
\end{array}
\end{aligned}
$$$$
5.9
$$

This shows that the steel exhibited slightly better behaviour than TA6V " $\alpha+\beta$ " DISCUSSION

Our results shows that, in the media investigated, steel withstands fatigue crack TA6V " $\beta$ " is characterized at least as well as, titanium alloys. On the other hand, .

account for any machining defects are treated as short cracks, it is necessary to lengths. To to increase in crack growth rates observed in the case of short crack of the crack, of an imaginary length equal to : the addition, to the effective length

$$
l_{0}=\frac{1}{\pi}\left(\frac{\Delta K_{t h}}{1.12 \Delta \sigma_{D}}\right)^{2}
$$
TA6V " $B$ "

- in 1 and 2 , the steel withstands fatigue crack initiation best, as

in all cases, the TA6V " $\alpha+\beta$ " seems to exhibit lower crack initiation ". 
Inally, a conservative estimate of the threshold stress range to ensure that a crack (small in comparison with the dimensions of the part considered) initiating from a
blunt notch does not propagate, is given by :

$$
\Delta S_{\text {th }}=K_{T} \Delta \sigma_{\text {th }}=\frac{\Delta K_{\text {th }}}{1.12 \sqrt{\pi\left(\ell+\ell_{0}\right)}}
$$

For the materials and media considered, Figure 10 shows $\Delta S$ th as a function of For length $\ell$ of a small crack in comparison with the dimensions of the part considered measured in air. This is assumed that the $\Delta K$ threshold was identical to the valu measured in air. This is a reasonable assumption threshold was identical to the value

. it is confirmed in other $12 \%$ chromium steels (Coulon, 1979),

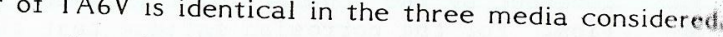
than $10 \mu \mathrm{m}$ (hion of this figure shows that, in the presence of notch cracks longer the best behaviour in the media considered.

\section{CONCLUSIONS}

With respect to fatigue crack initiation, $219 \mathrm{CD} 12-1$ steel seems to be at least as steel in medium the media considered. However, corrosion pits appeared in the other hand, TAGV to be competitive in absolo value in media investigated, and seems

for TA6V in relation seems to be more favoura

Finally, it may be considered that, in the presence of machining defects, " $B$ " tigated.

\section{REFERENCES}

Coulon, A. (1979). Corrosion fatigue of steam turbine blades. Paper at EPRI Workshop, Munchen (Germany).

Coulon, A., H. Saisse and B. Knosp (1983). Incubation time leading to fatigue crack initiation. Paper at ASTM 16th National Symposium on Fracture Columbus (USA).

Duncan, R.M., P.A. Blenkinsop and R. C. Meetham (Ed.), The development of Gaosey (1981). Titanium Alloys. In G.W. Publishers, 63-88 solution for ., K.N. Smith and T.M. Topper (1979). A strain based intensity factor Eylon, Dor for short fatigue cracks initiate from notches. In ASTM STP 677, 274-289. (1976). Effect of microstructure on notch fatigue Peterson, R.E. (1974). Stress Concentration Factions, 7A, 111 .

Topper, R.E. (1974). Stress Concentration Factors, John Wiley.

based on fracture. Fatigue Threshore mechanics. In J. Backlund, A.F. Blom and C.J. Beevers (Ed.) Fod R (1977). STa. 2, EMAS, 777-798.

EPRI AF-455, Finglatus of titanium blading for low pressure steam turbines. 